Original article

\title{
Effectiveness of various endodontic systems in treating teeth with C-shaped root canals
}

\author{
Irina V. Firsova, Natalia N. Trigolos, Nikolay N. Yaroshenko, Eduard S. Temkin, Maria V. Kabytova
}

Volgograd State Medical University, Volgograd, Russia

Received 23 April 2020, Revised 26 October 2020, Accepted 12 Febreary 2021

(C) 2020, Firsova I.V., Trigolos N.N., Yaroshenko N.N., Temkin E.S., Kabytova M.V.

(C) 2020, Russian Open Medical Journal

Abstract: Introduction - C-shaped configuration is amongst the most complicated root canal varieties requiring additional effort for successful endodontic treatment. The goal of this study was the laboratory comparison of the endodontic treatment efficiencies via XPendo vs. Gentlefile systems for the teeth with C-shaped root canals.

Material and Methods - In laboratory settings, 36 teeth with established C-shaped configuration, extracted for medical reasons (24 mandibular premolars and 12 mandibular second molars), underwent the root canal treatment by XP-endo (XP) and Gentlefile (GF) systems. Treatment quality was evaluated on the basis of dye penetration tests and examination of root dentinal surface with a scanning electron microscope. The significance of differences between the groups was assessed via Mann-Whitney $\mathrm{U}$ test.

Results - For GF instruments, the average size of stained area in the apical third of teeth was $3.33 \pm 2.73 \%$, while in the coronal third it amounted to $13.49 \pm 13.58 \%$. The results of using the XP instruments demonstrated the average size of stained area in the apical third equal to $15.45 \pm 12.48 \%$, while in the coronal third it was $37.30 \pm 14.06 \%$. The scanning electron microscopy revealed a rougher surface of dentin and the remnants of stained layer in root canals treated with GF system.

Conclusion - Thus, XP instruments exhibited a better treatment quality compared with GF system. The obtained data may justify the choice of instruments for endodontic teeth treatment in case of an intricate root canal system.

Keywords: C-shaped root canals, mandibular premolars, mandibular second molars, Gentlefile, XP-endo, scanning electron microscope.

Cite as Firsova IV, Trigolos NN, Yaroshenko NN, Temkin ES, Kabytova MV. Effectiveness of various endodontic systems in treating teeth with C-shaped root canals. Russian Open Medical Journal 2021; 10: e0114.

Correspondence to Irina V. Firsova. Address: 7/90 Nikolay Otrada St., Volgograd 400033, Russia. Phone: +79047760825. E-mail: pin177@rambler.ru.

\section{Introduction}

Root canal treatment aims at microbial eradication, removal of infected and necrotic residues of dental pulp tissue, and establishment of a root canal system to facilitate introduction of medicaments and obturation without causing iatrogenic damage to root dentin and periapical tissues [1].

One of important factors affecting treatment outcome is the anatomy of a root canal: specifically, it is unavoidable factor that is not controlled by a clinician, thereby defining the complexity of each individual case. C-shaped configuration is amongst the most complicated root canal varieties requiring additional effort for successful endodontic treatment and correction of conventional endodontic treatment methods [2, 3].

Historically, in 1911, Keith and Knowles were the first to document the C-shape of a root canal, while describing mandibular molars of Neanderthals, but they did not label the configuration they have discovered [4]. In 1979, Cooke and Cox have proposed the terms ' $\mathrm{C}$-shaped root' and ' $\mathrm{C}$-shaped root canal', which are still widely used by researchers and clinicians worldwide [5]. Previously, a C-shaped root canal was defined as a root canal, which had the shape of the letter $C$ in its cross section. Fan et al. introduced more distinct criteria in 2004 [6]:

1) Fused roots;
2) Longitudinal groove on the lingual or buccal surface of a root;

3) At least one cross section of a root canal should belong to the $\mathrm{C} 1, \mathrm{C} 2$ or $\mathrm{C} 3$ configurations sensu Fan's anatomic classification.

Haddad et al. (1999) emphasized that majority of intraoral targeted radiographs of $\mathrm{C}$-shaped root canals demonstrated the following features: fusion or close proximity of adjacent roots; enlarged distal root canal, along with a narrow medial root canal, and a blurred image of the third canal in between them; and in case of two very thinly connected roots, the X-ray may even show an image of two separate roots [7]. However, it is possible to accurately diagnose the C-shape solely via using the cone beam computed tomography (CBCT), giving a three-dimensional visualization of the root canal system.

Various causes of a C-shaped configuration formation have been suggested since the moment of its discovery. The failure of fusion in the Hertwig's epithelial root sheath is the most likely explanation of the $C$-shaped configuration $[6,8,9,10,11]$.

As for C-shaped canals in mandibular first premolars and second premolars, their incidence reaches $19.6 \%$ and $2.4 \%$, respectively. For instance, the occurrences of such configuration in second molars in Asia, Europe, America and Africa are up to $48.8 \%$, up to $14.1 \%$, up to $40.5 \%$, and up to $12.2 \%$ correspondingly [5, 12 - 
17]. According to our data, the prevalence of such configuration in Russia is $19.1 \%$ for first premolars, $3.8 \%$ for second premolars, and $10.0 \%$ for second molars [18].

Various techniques for preparation of C-shaped canals were proposed by different authors. These included preparation via using manually operated instruments (such as K- or H-files), endosonic root canal treatment, along with employing manual files, Gates-Glidden drills, and nickel-titanium rotary instruments, such as Profile, ProTaper and SAF [5, 19-23].

Endodontic treatment of complex root canals with manual utensils may lead to a significant number of complications during preparation and is more time consuming than their treatment with nickel-titanium (NiTi) rotary files [24]. Some systems were specifically designed for complex root canals, such as Gentlefile (MedicNRG, Kibbutz Afikim, Israel) and XP-endo (FKG Dentaire SA, Switzerland). These tools are made of various materials: Gentlefile (GF) of stainless steel, while XP-endo (XP) of nickel-titanium alloy with shape memory (M-Wire). So far, only a few studies on the efficiencies of the root canal preparation with XP and GF have been conducted, and none of those was a comparative study on teeth with C-shaped canals.

The goal of this study was the laboratory comparison of the endodontic treatment efficiencies via using two different endodontic systems (XP-endo vs. Gentlefile) for the teeth with Cshaped root canals.

\section{Material and Methods}

\section{Study objects}

The study was conducted on 36 teeth with C-shaped root canal system (24 mandibular premolars and 12 mandibular second molars) extracted for medical reasons. All extracted teeth were subject to CBCT. Only teeth with a C1, C2, or C3 configuration of at least one cross section, as defined by Fan's anatomic classification, were considered $\mathrm{C}$-shaped. All teeth were randomly allocated to two treatment groups, containing 18 teeth each (12 premolars and 6 second molars), and each group had its specific instrumental treatment.

\section{Methodology and instruments}

Teeth in Group I received the root canal treatment by XP system, and teeth in Group II were treated with GF system, following the protocols recommended by the manufacturers. When conducting the present study, the teeth from the XP group were preheated in a thermostat up to a human body temperature, since the instrument is made of a nickel-titanium alloy with shape memory. Alternatively, three premolars were treated with manual stainless-steel files (Mani, Japan) following the step-back technique. As an irrigant, we used a $3 \%$ sodium hypochlorite solution (Belodez, JSC VladMiVa) with passive ultrasonic activation. After their treatment, root canals were rinsed with $10 \mathrm{ml}$ of sterile distilled water and dried with paper points. One endodontically untreated premolar was taken for control. The working length of the root canal was measured using CBCT.

\section{Dye penetration test}

All extracted teeth in both groups, after preparation with XP and GF instruments, were subjected to the test on dye penetration in the apical, middle and coronal thirds of the root canal. The surface of roots was coated with two layers of varnish and dried. Then the roots were filled with a dye ( $2 \%$ methylene blue) injected with a syringe at the room temperature (Figure 1). After 20 minutes, they were thoroughly rinsed under flowing water until full removal of the dye. The root canals were dried with paper points.

Using dental separating disk and water cooling, the samples were sectioned horizontally in the mesiodistal direction into three parts representing apical, middle, and coronal thirds. The prepared sections of root canals were photographed. The obtained digital photographs were used to calculate dye penetration area, total area of root cross section, and luminal area of root canals, using the ImageJ software, version $1.52 \mathrm{~h}$ (Wayne Rasband, National Institutes of Health, USA).

\section{Scanning electron microscope}

All samples were investigated with scanning electron microscopy (SEM). To do so, the prepared teeth were cut along the longitudinal axis with a diamond disk, under a constant water cooling, and examined with Versa 3D DualBeam SEM (FEI, USA). Digital microphotographs of root canal dentin were taken in its middle third (Figure 2).

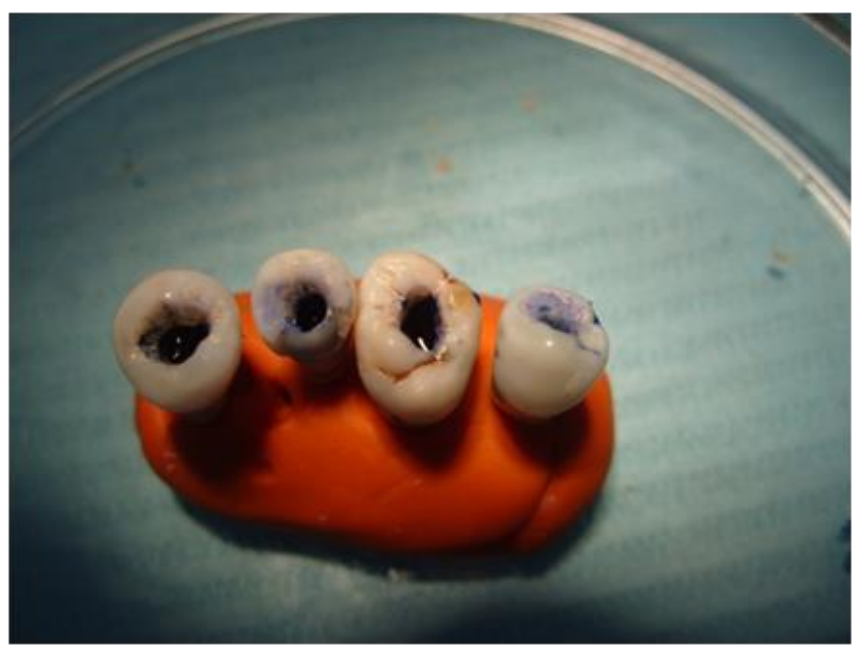

Figure 1. Prepared samples: root canals filled with $2 \%$ methylene blue

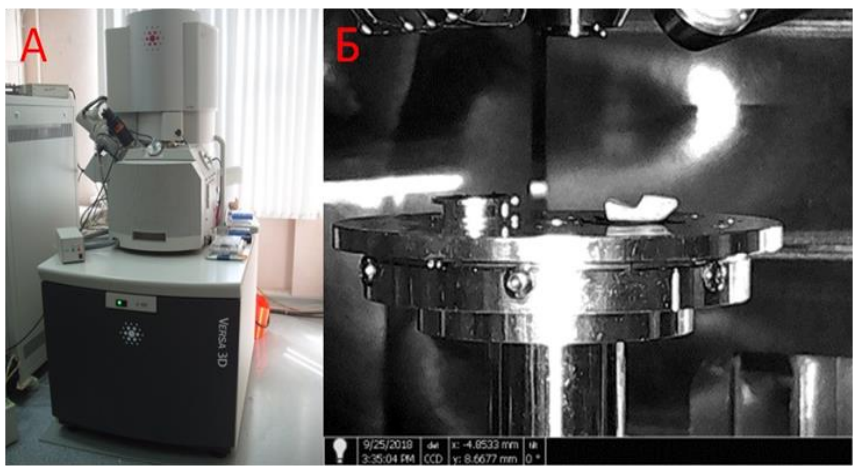

Figure 2. Scanning electron microscope: a) General view; b) Vacuum chamber with samples under study 


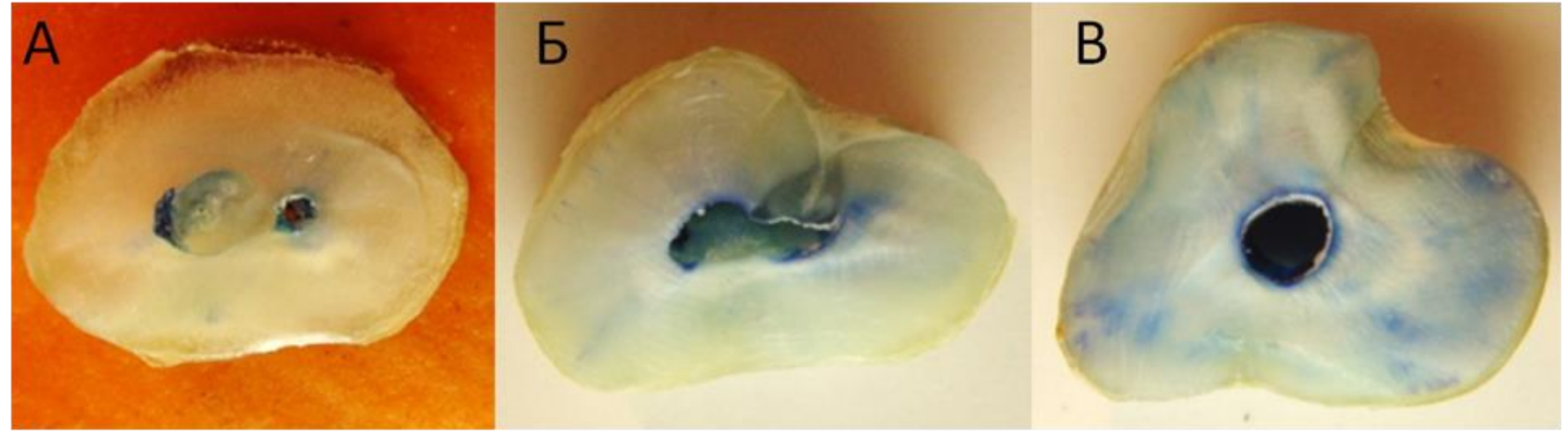

Figure 3. Cross sections of the first premolars with different stained areas after the treatment with Gentlefile instruments: a) Apical part; b) Middle part; c) Coronal part.
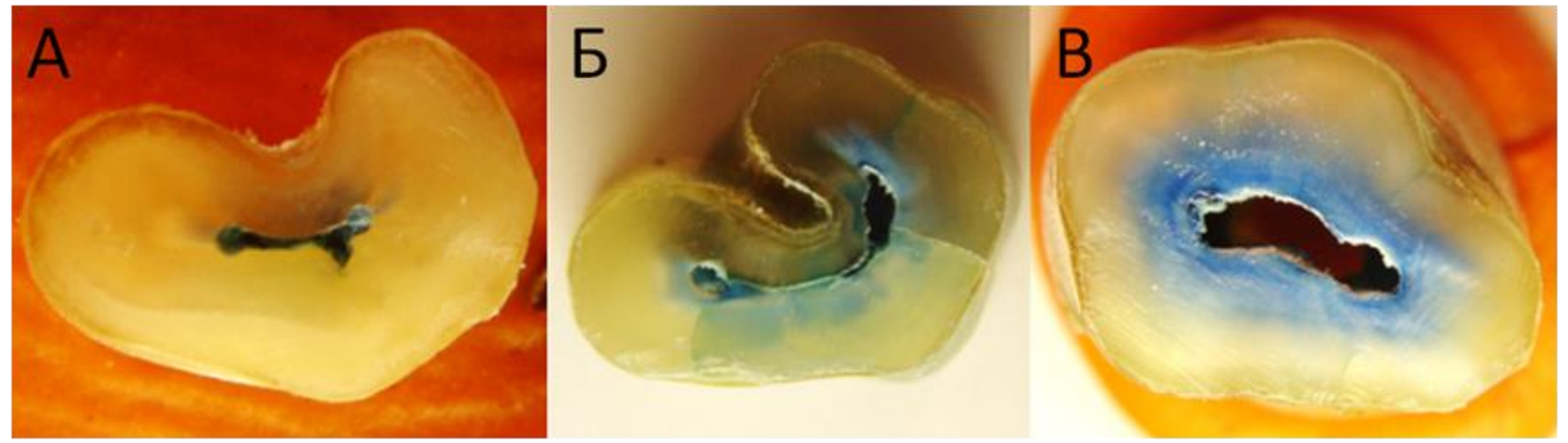

Figure 4. Cross sections of the first premolars with different stained areas after the treatment with XP-endo instruments: a) Apical part; b) Middle part; c) Coronal part.

\section{Statistical analysis}

Statistical analysis was performed using RStudio (version 1.2.1335). A small sample size did not allow us using parametric tests. Hence, we chose in favour of a non-parametric MannWhitney $U$ test to compare the distributions of two groups with numerical variables. In order to demonstrate the key features of two samples graphically, paired boxplots for each third were built.

\section{Results}

The results of our laboratory study demonstrated the possibility of using both GF and XP instruments for conducting an effective treatment of even intricate $\mathrm{C}$-shaped root canal systems. However, differences in stained areas of dentine in apical, middle and coronal root parts on cross sections of teeth implied significantly different quality of root canal treatment outcomes (Figures 3 and 4).

When conducting the root canal treatment with GF system, the average size of stained area was $3.33 \pm 2.73 \%$ in the apical third, $7.87 \pm 5.63 \%$ in the middle third, and $13.49 \pm 13.58 \%$ in the coronal third of the teeth. The minimum and maximum sizes of the stained area were $0.18 \%$ and $57.74 \%$, respectively. When performing the root canal treatment with XP system, the mean value of stained area size was $15.45 \pm 12.48 \%$ in the apical third, $46.21 \pm 25.57 \%$ in the middle third, and $37.30 \pm 14.05 \%$ in the coronal third of the teeth. The minimum and maximum sizes of the stained area were $0.79 \%$ and $98.45 \%$, correspondingly. By presenting the graphical summary of our data via paired boxplots, it is easy to compare how differently two samples are distributed. The shift in distributions of both samples is noticeable in all three paired comparisons for apical, middle and coronal thirds of the teeth (Figure 5, 6, 7).

Mann-Whitney $U$ test demonstrated that distributions of two samples were not similar. The results exhibited statistical significances with p-values of $0.0002,9.917 \times 10^{-9}$ and $2.533 \times 10^{-6}$ for mean sizes of stained areas in the apical, middle and coronal thirds, respectively.

The microphotograph of the root canal wall treated with GF system exposed the presence of a large number of filings blocking an access to dentinal tubules, and the smear layer was barely removed. A few dentinal tubules were open, while most were closed, and the dentinal surface was uneven (Figure 8).

The microphotograph of the root canal wall treated with XP system revealed that there was virtually no smear layer and there were significantly more open dentinal tubules. The dentinal surface was much smoother than after using the GF instruments, as well as compared with the untreated sample (Figure 9).

As shown in Figure 10, the microphotograph of the root canal wall treated with conventional manual step-back technique showed that the surface of the canal wall was totally covered with the smear layer, including dentin particles. The dentinal tubules were completely or partially closed, and the dentinal surface appeared uneven (comparable to the surface of the samples, which underwent the treatment with GF instruments). 


\section{Comparison of distribution of stained areas in apical thirds}

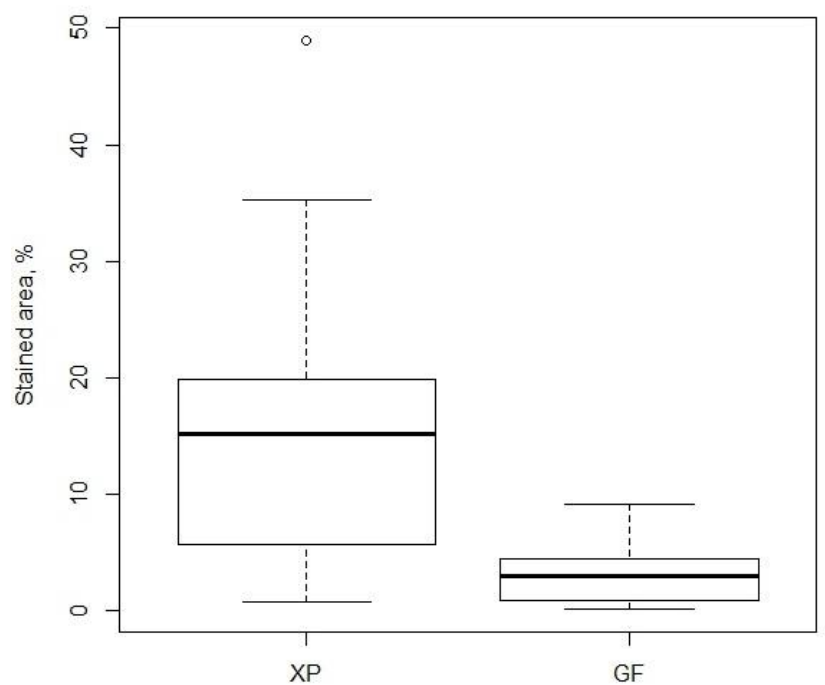

Figure 5. Comparison of stained area distribution in the apical thirds of the teeth treated with XP-endo and Gentlefile tools.

\section{Comparison of distribution of stained areas in middle thirds}

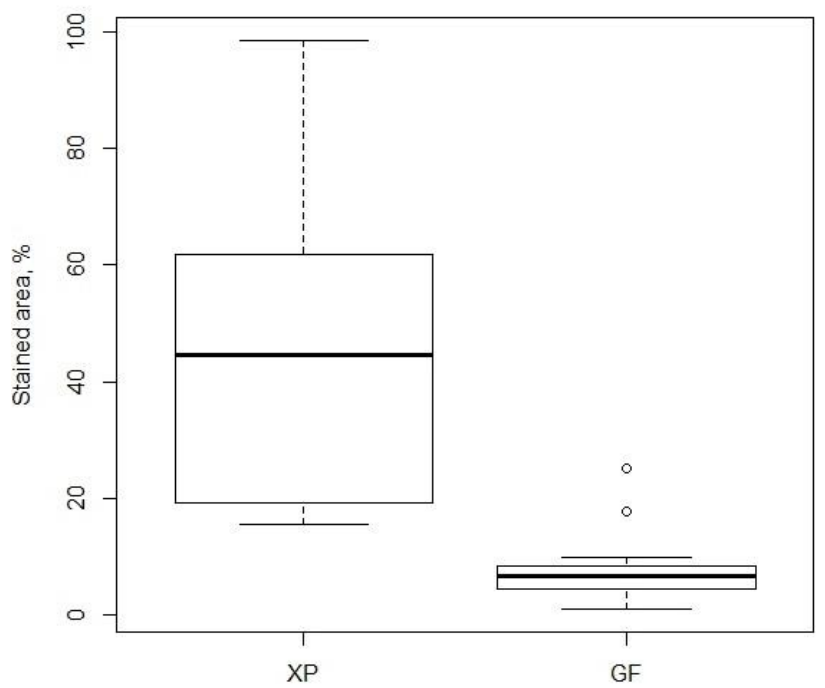

Figure 6. Comparison of stained area distribution in the middle thirds of the teeth treated with XP-endo and Gentlefile tools.

\section{Discussion}

While performing a C-shaped root canal treatment, a special attention should be paid to the isthmus between different canals, which is a narrow ribbon-like connection between two root canals. The isthmus may contain pulp or pulp tissue residues, and therefore it should be considered a bacterial reservoir [25]. Broad connections and small surface area of these canals eliminate complete cleansing when using traditional manual instruments. Also, there is a high risk of an accidental perforation during the treatment of root canals since the minimum wall thickness of such teeth is just $0.17 \mathrm{~mm}[26]$.

In the XP group, the average size of the stained area for all cross sections was greater than in the GF group. This can be explained by the fact that the XP system is made of a nickel- titanium alloy with shape memory. This alloy can exist in two phases: martensitic and austenitic [27]. At the human body temperature, it transforms into the austenitic phase, bends and takes the shape of a root canal, having a size of 30 and a taper of 0.04 . The manufacturer does not recommend removing the XP file from the tube before its insertion into the handpiece, as well as touching it with fingers, in order to avoid its heating. Before the insertion into the root canal, the XP file should be cooled down with a special spray: in our case, it was Pharmaethyl spray (Septodont, France). In the course of conducting our research, the teeth in the XP group were preheated in a thermostat up to the body temperature, which would not be required in a clinical situation. Even complying with all requirements, the stained area in the apical third of the root canal was solely $15.45 \pm 12.48 \%$, which was indicative of insufficient treatment. Still, the treatment results of root canals with XP instruments were better than in case of using the GF system.

When using the GF system, the manufacturer recommends performing up and down movements inside root canals at the maximum possible speed. This stage depends on manual skills oa a dentist, which may affect the quality of a root canal treatment. On average, the stained area was rather small, with the maximum size in the coronal third of $13.49 \pm 13.58 \%$. Its mean size in the apical third was just $3.33 \pm 2.73 \%$, which indicated the extremely low effectiveness of treating this section of a C-shaped root canal. During its work, GF scrapes the dentin, unlike XP, which cuts it off, and this circumstance affects the number of open dentinal tubules. In the course of treating root canals with GF system, no accidental perforations were made.

SEM microphotographs showed that the GF file left significantly more debris in root canals compared with the XP file. The GF system left comparatively rougher dentinal surfaces, fewer open dentinal tubules, and presence of the smear layer.

For all cases, the CBCT-measured working length of the root canal matched its actual working length.

\section{Comparison distribution of stained areas in coronal thirds}

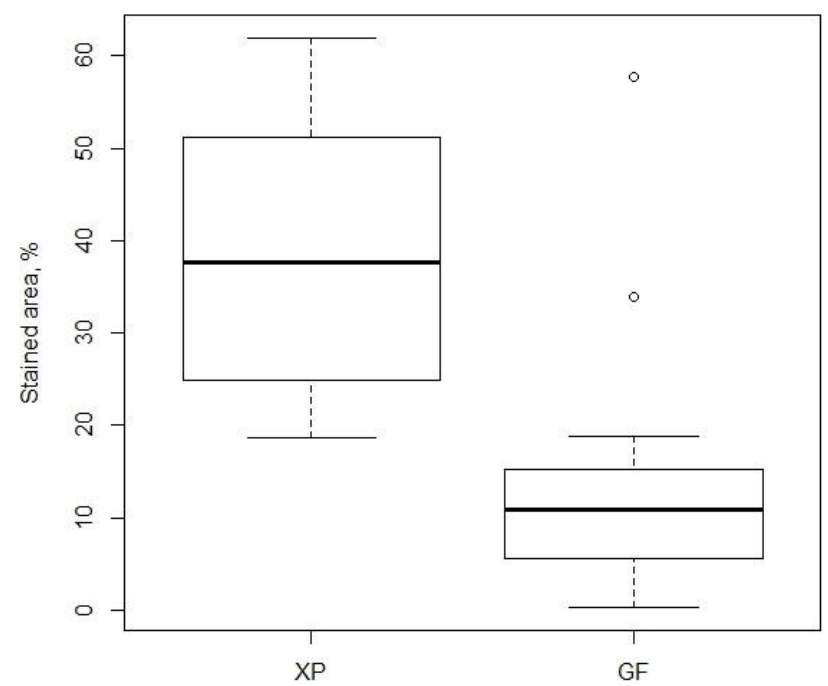

Figure 7. Comparison of stained area distribution in the coronal thirds of the teeth treated with XP-endo and Gentlefile tools. 


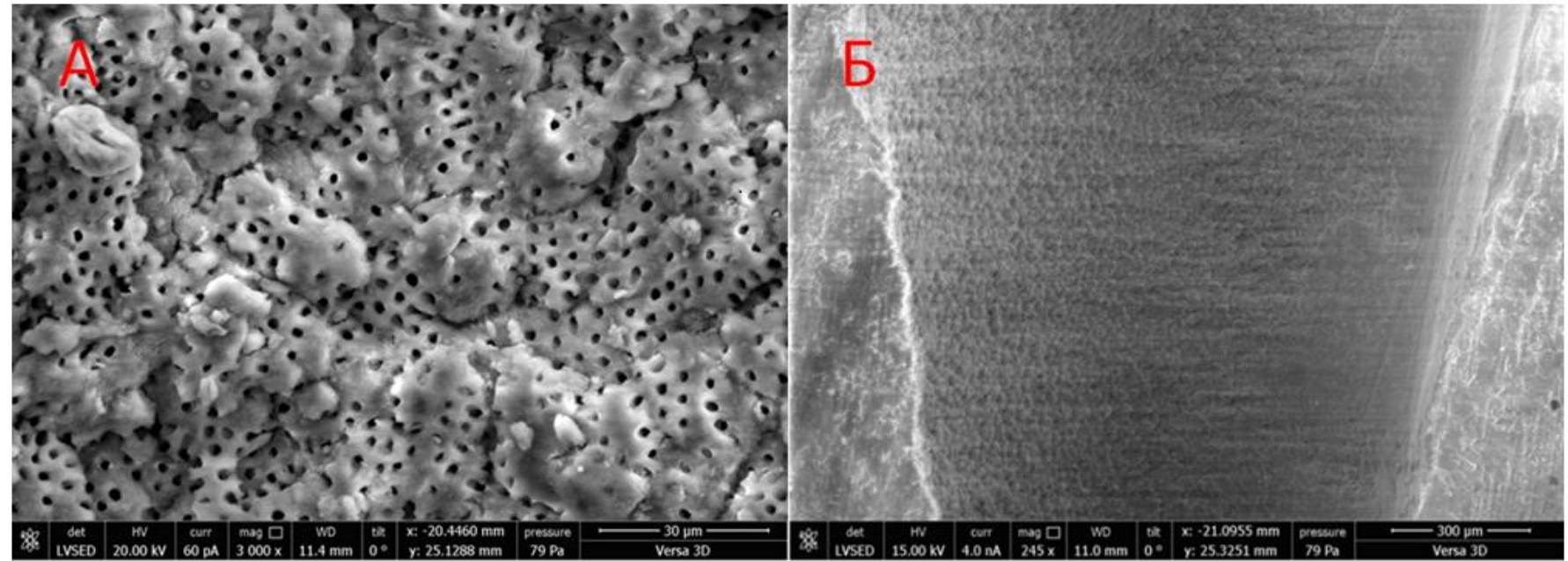

Figure 8. Scanning electron microscopy of the root dentinal surface after preparation of the middle third of the root canal with Gentlefile system at magnifications: a) 3000x; b) 245x. Dentinal tubules are closed, a large number of filings, the smear layer is present.

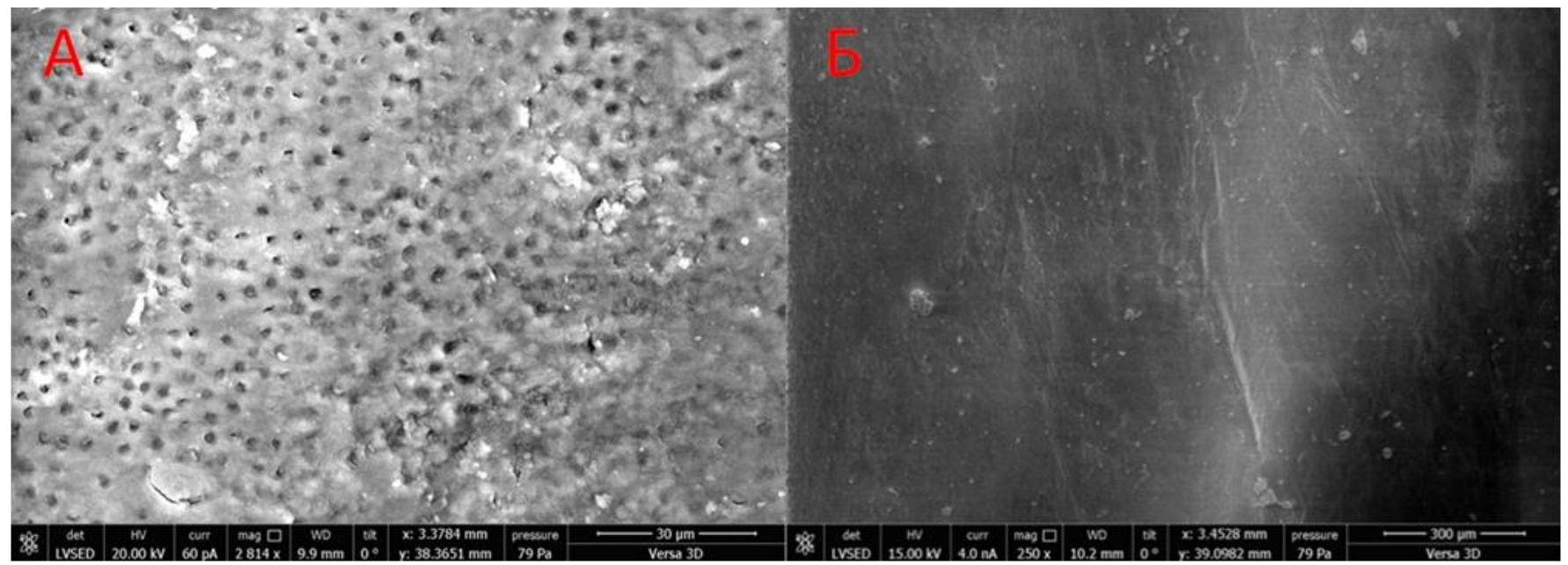

Figure 9. Scanning electron microscopy of the root dentinal surface after preparation of the middle third of the root canal with XP-endo system at magnification: a) 2814x; b) 250x. Dentinal tubules are fully open, the smear layer is absent.

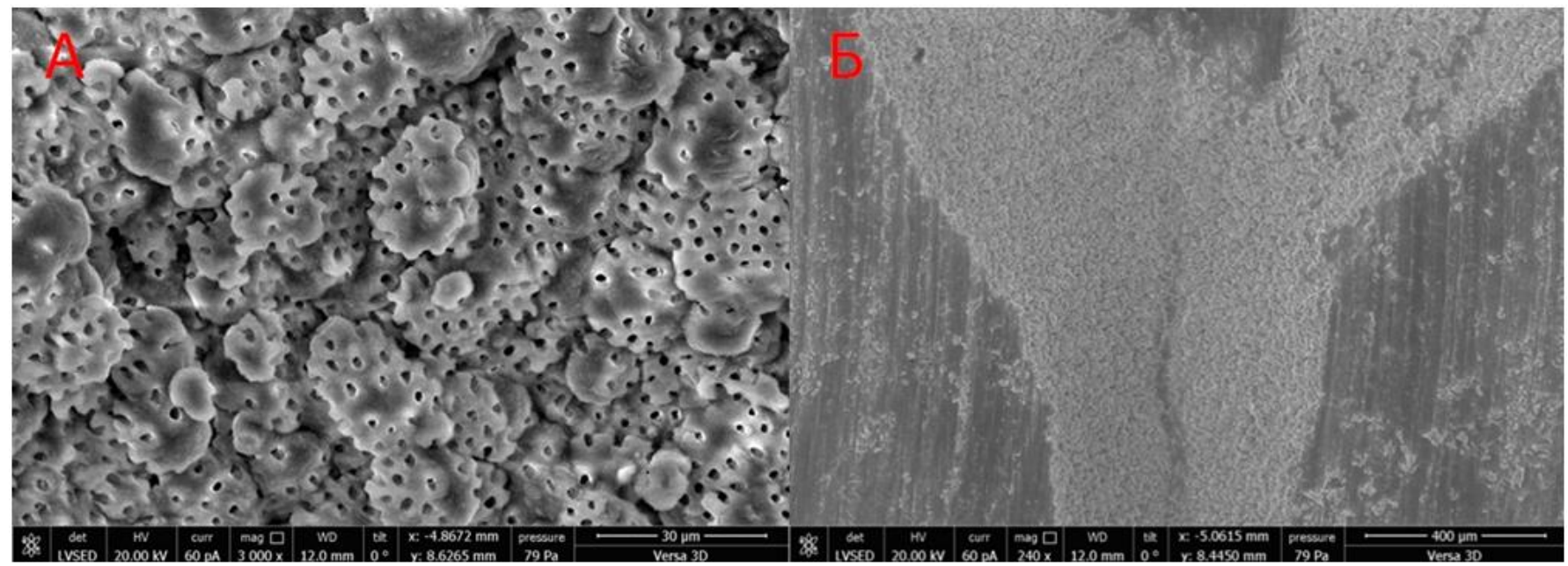

Figure 10. Scanning electron microscopy of the root dentinal surface after preparation of the middle third of the root canal with K-Files stainless steel endodontic instruments at magnification: a) 3000x; b) 240x. The surface of dentine is uneven, a large number of closed dentinal tubules, the smear layer is present. 


\section{Conclusion}

The study results implied that XP system was more effective in treating teeth with a $\mathrm{C}$-shaped root canal configuration than the GF system, and confirmed the fact that C-shaped canals require greater attention at all stages of endodontic treatment. Such configuration represents a daunting challenge to contemporary endodontic treatment systems.

\section{Limitation}

The presented study was conducted solely on extracted teeth, which places a certain restriction on extrapolating the obtained results on reallife medical cases. Tooth quality varied due to the differences in patient health condition and individual traits, and our laboratory experiment may not have fully imitated the conditions of in vivo tissue treatment.

\section{Ethical approval}

This study did not include human or animal subjects.

\section{Conflict of interest}

The authors report no conflicts of interest pertaining to any of the products or companies discussed in this article.

\section{References}

1. Schilder H. Cleaning and shaping the root canal. Dent Clin North Am 1974; 18(2): 269-296. https://pubmed.ncbi.nlm.nih.gov/4522570/.

2. Walid $\mathrm{N}$. The use of two pluggers for the obturation of an uncommon C-shaped canal. J Endod 2000; 26(7): 422-424. https://doi.org/10.1097/00004770-200007000.

3. Liewehr FR, Kulild JC, Primack PD. Obturation of a C-shaped canal using an improved method of warm lateral condensation. J Endod 1993; 19: 474-477. https://doi.org/10.1016/S0099-2399(06)80537-6.

4. Keith A, Knowles FH. A description of teeth of Palaeolithic man from Jersey. J Anat Physiol 1911; 46(Pt 1): 12-27. https://pubmed.ncbi.nlm.nih.gov/17232906/.

5. Cooke HG 3rd, Cox FL. C-shaped mandibular canal configurations in molars. J Am Dent Assoc 1979: 99(5); 836-839. https://doi.org/10.14219/jada.archive.1979.0402.

6. Fan B, Cheung GS, Fan M, Gutmann JL, Bian Z. C-shaped canal system in mandibular second molars: Part I - Anatomical features. J Endod 2004; 30(12): 899-903. https://doi.org/10.1097/01.don.0000136207.12204.e4.

7. Haddad GY. Nehme WB, Ounsi HF. Diagnosis, classification, and frequency of $\mathrm{C}$-shaped canals in mandibular second molars in the Lebanese population. J Endod 1999; 25(4): 268-271. https://doi.org/10/1016/S099-2399(99)80157-5.

8. Zheng $Q$, Zhang L, Zhou X, Wang Q, Wang $Y$, Tang L, et al. C-shaped root canal system in mandibular second molars in a Chinese population evaluated by cone-beam computed tomography. Int Endod J 2011; 44(9): 857-862. https://doi.org/10.1111/j.13652591.2011.01896.x

9. Orban B, Mueller $\mathrm{E}$. The development of bifurcation of multirooted teeth. J Am Dent Assoc 1929; 16: 297-319.

10. Fan B, Pan Y, Gao Y, Fang F, Wu Q, Gutmann JL. Three-dimensional morphologic analysis of isthmuses in the mesial roots of mandibular molars. J Endod 2010; 36(11): 1866-1869. https://doi.org/10.1016/i.joen.2010.08.030.

11. Wang Y, Guo J, Yang HB, Han X, Yu Y. Incidence of C-shaped root canal systems in mandibular second molars in the native Chinese population by analysis of clinical methods. Int J Oral Sci 2012; 4(3): 161-165. https://doi.org/10.1038/ijos.2012.42.

12. Weine FS. The C-shaped mandibular second molar: Incidence and other considerations. Members of the Arizona Endodontic Association.
$J$ Endod 1998; 24(5): 372-375. https://doi.org/10.1016./S00992399(98)80137-4.

13. Lu TY, Yang SF, Pai SF. Complicated root canal morphology of mandibular first premolar in a Chinese population using the crosssection method. J Endod 2006; 32(10): 932-936. https://doi.org/10.1016.i.joen.2006.04.008.

14. Gu YC, Zhang YP, Liao ZG, Fei XD. A micro-computed tomographic analysis of wall thickness of $\mathrm{C}$-shaped canals in mandibular first premolars. J Endod 2013; 39(8): 973-976. https://doi.org/10.4103/0972-0707.131785.

15. Manning SA. Root canal anatomy of mandibular second molars. Part II: C-shaped canals. Int Endod J 1990; 23(1): 40-45. https://doi.org/10.1111/j.1365-2591.1990.tb00801.x.

16. Rahimi S, Shahi S, Lotfi M, Zand V, Abdolrahimi M, Es'haghi R. Root canal configuration and the prevalence of C-shaped canals in mandibular second molars in an Iranian population. J Oral Sci 2008; 50 (1): 9-13. https://doi.org/10.2334/josnusd.50.9.

17. Zhang $\mathrm{R}$, Yang $\mathrm{H}, \mathrm{Yu} X$, Wang $\mathrm{H}, \mathrm{Hu} \mathrm{T}$, Dummer PM. Use of $\mathrm{CBCT}$ to identify the morphology of maxillary permanent molar teeth in a Chinese subpopulation. Int Endod J 2011; 44(2): 162-169. https://doi.org/10.1111/j.1365-2591.2010.01826.x.

18. Trigolos NN, Firsova IV, Makedonova YuA, Yaroshenko NN. Combinations C-shaped root canals in mandibular premolars and second mandibular molars with each other and with the complex channels of other teeth of the lower jaw according to the cone-beam computed tomography. Endodontics Today 2017; (1): 20-23. Russian. https://www.elibrary.ru/item.asp?id=29265625.

19. Benenati FW. Maxillary second molars with two palatal canals and a palatogingival groove. J Endod 1985; 11(7): 308-310. https://doi.org/10.1016/s0099-2399(85)80163-1.

20. De Moor RJ. C-shaped root canal configuration in maxillary first molars. Int Endod J 2002; 35(2): 200-208. https://doi.org/10.46/j.13652591.2002.00461.x.

21. Barnett F. Mandibular molars with C-shaped canal. Endod Dent $\begin{array}{lll}\text { Traumatol 1986; 2(2): } & \text { 79-81. }\end{array}$ https://pubmed.ncbi.nlm.nih.gov/3459655.

22. Solomonov $M$, Paqué $F$, Fan B, Eilat $Y$, Berman $L$ H. The challenge of $C$ shaped canal systems: a comparative study of the self-adjusting file and ProTaper. J Endod 2012; 38(2): 209-214. https://doi.org/10.1016/j.joen.2011.10.022.

23. Bolger WL, Schindler WG. A mandibular first molar with a C-shaped root configuration. J Endod 1988; 14(10): 515-519. https://doi.org/10.1016/s0099-2399(88)80110-9.

24. Yin $X$, Cheung GS, Zhang $C$, Masuda YM, Kimura $Y$, Matsumoto $K$. Micro-computed tomographic comparison of nickel-titanium rotary versus traditional instruments in C-shaped root canal system. J Endod 2010; 36: 708-712. https://doi.org/10.1016/j.joen.2010.01.003.

25. Vertucci FJ. Root canal morphology and its relationship to endodontic procedures. Endodontic Topics 2005; 10(1): 3-29. https://doi.org/10.1111/j.1601-1546.2005.00129.x.

26. Gu YC, Zhang YP, Liao ZG, Fei XD. A micro-computed tomographic analysis of wall thickness of C-shaped canals in mandibular first premolars. J Endod 2013; 39(8): 973-976. https://doi.org/10.1016/j.joen.2013.04.039.

27. Versiani MA, Carvalho KKT, Mazzi-Chaves JF, Sousa-Neto MD. Microcomputed tomographic evaluation of the shaping ability of XP-endo Shaper, iRaCe, and EdgeFile systems in long oval-shaped canals. Endod 2018; 44(3): 489-495. https://doi.org/10.1016/j.joen.2017.09.008.

\section{Authors:}

Irina V. Firsova - MD, Professor, Chair of the Department of Therapeutic Dentistry, Volgograd State Medical University, Volgograd, Russia. http://orcid.org/0000-0002-1293-5650. 
Natalia N. Trigolos - PhD, Associate Professor, Department of Therapeutic Dentistry, Volgograd State Medical University, Volgograd, Russia. http://orcid.org/0000-0002-2301-1082.

Nikolay N. Yaroshenko - graduate student, Department of Therapeutic Dentistry, Volgograd State Medical University, Volgograd, Russia. http://orcid.org/0000-0002-0465-0065.

Eduard S. Temkin - MD, Professor, Department of Therapeutic Dentistry, Volgograd State Medical University, Volgograd, Russia. http://orcid.org/0000-0002-6163-7465

Maria V. Kabytova - Associate Professor, Department of Therapeutic Dentistry, Volgograd State Medical University, Volgograd, Russia. http://orcid.org/0000-0002-3755-6470. 